\title{
Ligation of the hepatic artery in the treatment of heart failure due to hepatic haemangiomatosis
}

\author{
M. O. RAKE, M. M. LIBERMAN, J. L. DAWSON, RACHEL EVANS, \\ E. B. RAFTERY, J. LAWS, AND ROGER WILLIAMS \\ From King's College Hospital and the Princess Louise Hospital, London
}

SUMMARY An infant presenting with high-output cardiac failure and a single large diffuse haemangioma of the liver is described. Corticosteroid therapy failed to produce any improvement, but hepatic artery ligation was followed by dramatic disappearance of the signs of cardiac failure and a decrease in the size of the liver without any evidence of lasting liver damage.

Small and sometimes multiple haemangiomata of the liver may remain undetected throughout life, being discovered only at necropsy (Shumacker, 1942). Larger or diffuse haemangiomata throughout the whole or part of the liver at any age are rare. In infancy such lesions can involve the whole liver and may enlarge progressively during the first six to 12 months of life. After a variable time during which the lesions remain stationary they often regress spontaneously in the second year of life. In the majority of cases cutaneous lesions are also found, either being present at birth or appearing during the first two months of life (DeLorimier, Simpson, Baum, and Carlsson, 1967). The major effect of these large and diffuse haemangiomata of the liver in infancy is to act as arteriovenous shunts which can lead to a state of high-output cardiac failure. The classical clinical triad is then one of cutaneous haemangiomatosis, hepatomegaly, and congestive cardiac failure. Of the 25 cases with this triad collected from the literature by DeLorimier et al (1967). only three survived with conservative management of the heart failure. These authors suggested that ligation of the hepatic artery might be of value and they reported its successful use in one case. A further patient treated successfully by hepatic-artery ligation is now reported.

\section{Case History}

A.E., a male child weighing $3.4 \mathrm{~kg}$ at birth on
10 December 1968, was noticed to have developed cutaneous haemangiomata on the occiput, the neck, and at the base of the left little finger five days later. He was perfectly well until about three weeks after birth when he developed an infection of the upper respiratory tract and severe respiratory distress for which he was admitted to hospital on 5 January 1969.

On admission he was in severe respiratory distress with a respiratory rate of $80 /$ minute. His pulse was $190 / \mathrm{min}$ and collapsing in nature. A pansystolic murmur was heard anteriorly and posteriorly over the whole of the thorax and the pulmonary second sound was accentuated. There were bilateral basal rales. The liver was large and pulsatile, with a thrill and a loud too-and-fro murmur which was audible maximally in the epigastrium. The spleen was also enlarged. A diagnosis of multiple haemangiomatosis of the liver was made. He was treated with digitalis and diuretics for the cardiac failure and with a combination of ampicillin and cloxacillin for the respiratory infection. On this regime his respiratory rate fell to between 50 and $70 / \mathrm{min}$ but the pulse rate did not fall significantly. He was transferred to King's College Hospital for further investigations and treatment.

INVESTIGATIONS

On admission his haemoglobin was $9.7 \mathrm{~g} / 100 \mathrm{ml}$, MCHC $35 \%$, WBC $8,000 / \mathrm{cmm}$, and platelets Received for publication 31 October 1969. 
$245,000 / \mathrm{cmm}$. Blood volume was markedly raised with a normal red cell mass (Table), the net effect being a haemodilutional anaemia with a low peripheral venous haematocrit. A chest film showed cardiac enlargement (cardio-thoracic ratio $60 \%$ ) with pulmonary plethora. A plain film of the abdomen showed no abnormal calcification. An ECG showed $T$ wave inversion in V1-4 and right ventricular hypertrophy.

\begin{tabular}{llll}
\hline Blood Measurements & $\begin{array}{l}\text { Before } \\
\text { Surgery }\end{array}$ & $\begin{array}{l}\text { After } \\
\text { Surgery }\end{array}$ & $\begin{array}{l}\text { Normal } \\
\text { Range }\end{array}$ \\
\hline Red cell mass $(\mathrm{ml})$ & 120 & 121 & $120-128$ \\
$(\mathrm{ml} / \mathrm{kg})$ & $28 \cdot 1$ & $27 \cdot 6$ & \\
Plasma volume $(\mathrm{ml})$ & 312 & 208 & $130-285$ \\
$(\mathrm{ml} / \mathrm{kg})$ & $73 \cdot 4$ & $47 \cdot 2$ & \\
Blood volume $(\mathrm{ml})$ & 432 & 329 & $268-309$ \\
$(\mathrm{ml} / \mathrm{kg})$ & $101 \cdot 5$ & $74 \cdot 8$ & \\
Venous haematocrit & $27 \cdot 4$ & $36 \cdot 8$ & $40-57 \cdot 5$ \\
\hline
\end{tabular}

Table Results of blood volume measurements before and after surgery

Liver function tests showed plasma total bilirubin to be $0.5 \mathrm{mg} / 100 \mathrm{ml}$, alkaline phosphatase $9.5 \mathrm{KA}$ units $/ 100 \mathrm{ml}$, aspartate-amino transferase $105 \mathrm{IU} / \mathrm{ml}$, alanine-amino transferase $51 \mathrm{IU} / \mathrm{ml}$, and prothrombin time $15 \mathrm{sec}$ (control 15 seconds). A liver scan ( $\mathrm{Tc}^{99} \mathrm{~m}$ sulphur-colloid) showed that the liver was enlarged but no filling defects were present; the spleen was also enlarged. An aortogram was performed by Seldinger's technique using a Riley needle and no. 3 nylon catheter passed to the level of D.12 via the right femoral artery. Two injections of $8 \mathrm{ml}$ Hypaque 45 were made with the patient supine and in the right posterior oblique position. The main hepatic artery was very big, with many large, irregular intrahepatic branches (Fig. 1a and b). Small, relatively avascular areas indicated the normal liver substance (Fig. 1c). The hepatic veins were huge and there was quite a dense opacification of the right atrium (Fig. 1d). The aorta tapered suddenly below the level of the coeliac axis artery and the renal arteries were normal.

\section{SUBSEQUENT COURSE}

Shortly after admission the patient developed bronchiolitis with wheezing and cardiac failure. Prednisone $5 \mathrm{mg}$ twice daily was started on 24 January 1969 and a further course of ampicillin and cloxacillin given. The bronchiolitis improved on this therapy but there was no remission of the cardiac failure. He was considered unfit for surgery at this time. A short trial of radiotherapy, in which the patient received a total of 390 rads to the liver area, was given, but there was little improvement. The cardiac failure persisted, the chest film was unchanged, and a further liver scan showed no reduction in the size of the liver.

On 12 February 1969 laparotomy and hepatic artery ligation was performed. The liver was

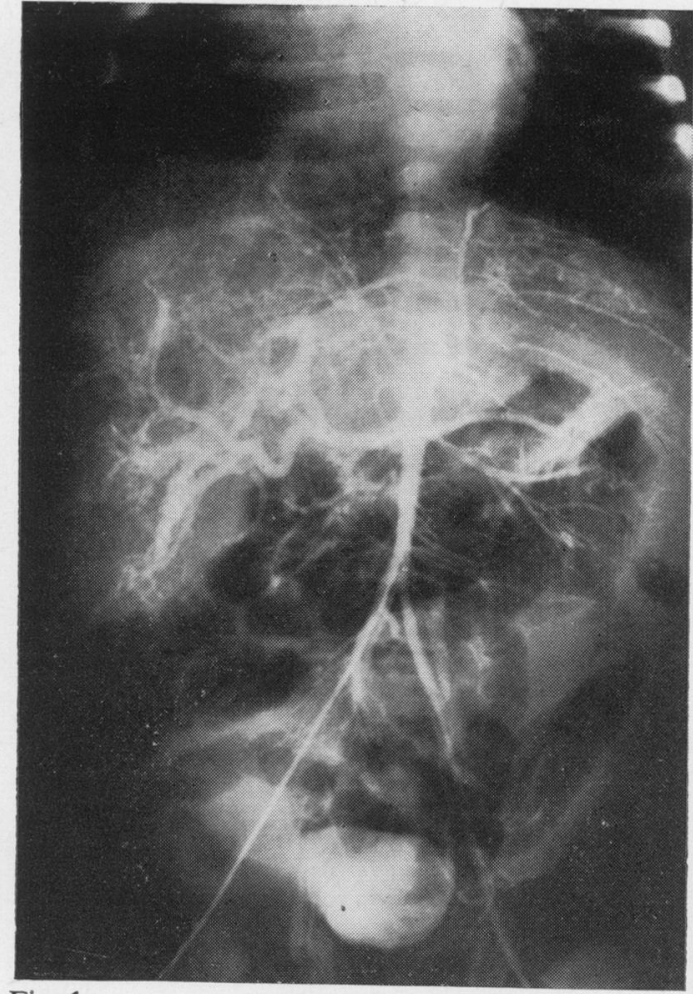

Fig. 1a.

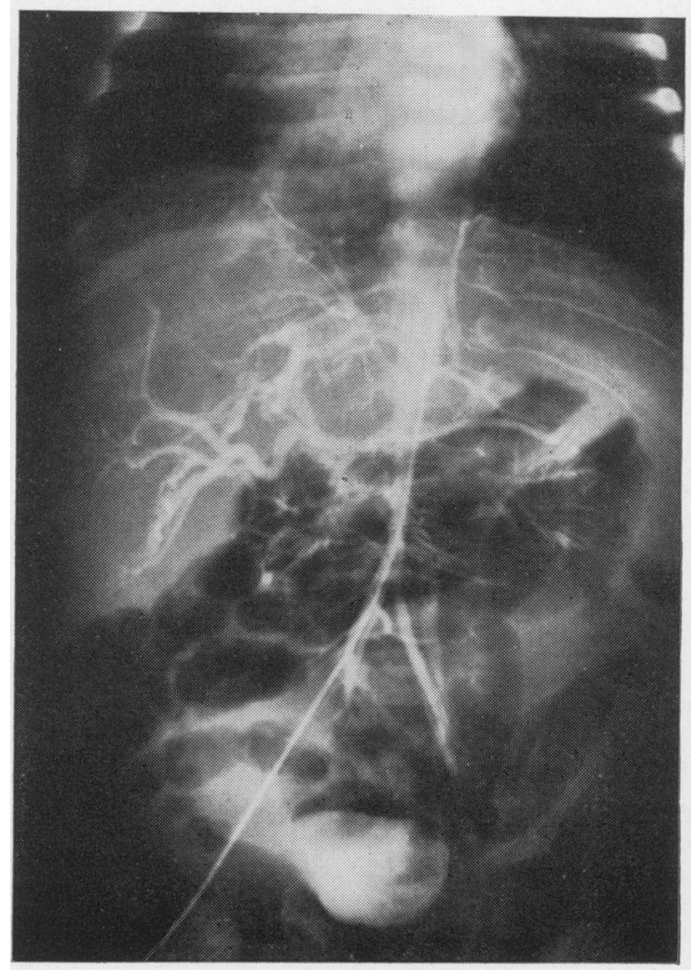

Fig. 1b. 


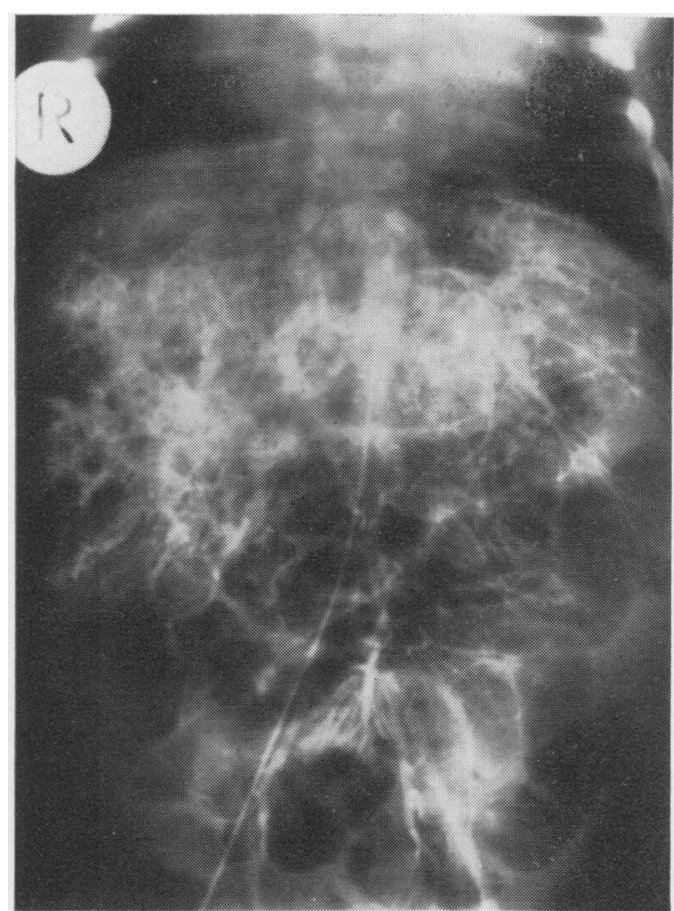

Fig. 1c.

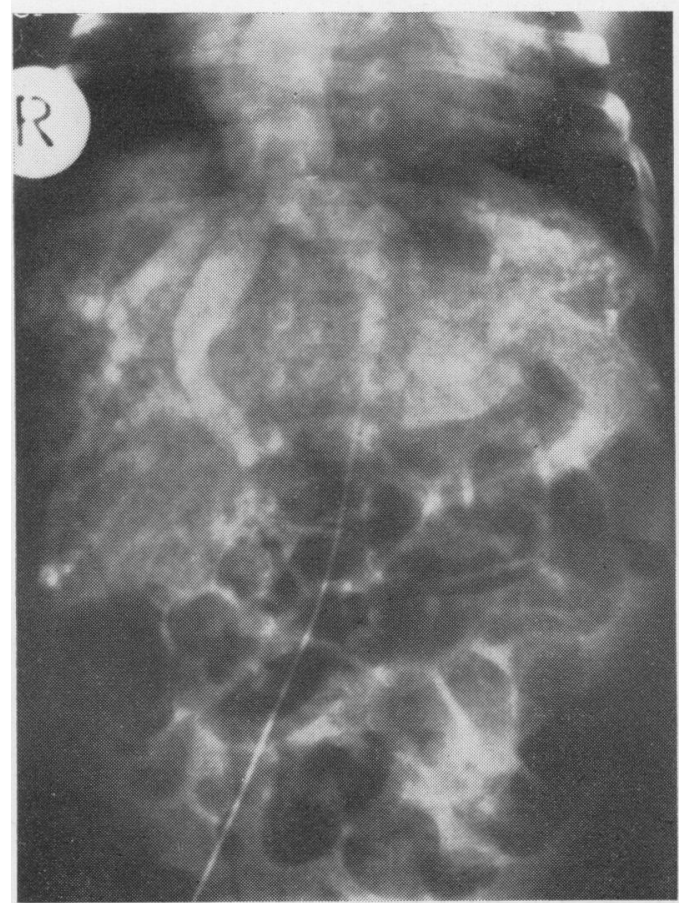

Fig. 1d.

Fig. 1 Preoperative aortograms: (a) and (b), early and late arterial phase shows a very large hepatic artery with irregular intrahepatic branches. The aorta below the origin of the hepatic artery is small.

(c) The hepatographic phase shows dense opacification of the liver with non-opacified areas probably representing normal liver tissue. (d) Venous phase showing large hepatic veins draining into right atrium. found to be enlarged, lobulated, and purplish in colour with both the cystic and hepatic arteries enlarged and tortuous. The common hepatic artery was ligated in the porta hepatis 1 inch distal to the origin. After the operation there was a dramatic improvement in the cardiac state. Within 24 hours the pulse rate fell to $120 / \mathrm{min}$ and the respiratory rate fell to normal. Liver function, as determined by routine liver function tests, was little disturbed. The aspartate-amino transferase reached a maximum of $116 \mathrm{IU} / \mathrm{ml}$ on the second day after operation.

During the next four weeks the child continued to do well and began to gain weight. The cardiac failure disappeared and the liver diminished in size and was only just palpable when he was discharged home one month later. It was no longer pulsatile and no bruit could be heard in the epigastrium.

A repeat aortogram on 3 March 1969 showed the proximal $2.5 \mathrm{~cm}$ of the hepatic artery to be patent up to the site of the ligature. Beyond this, circulation into the liver was carried through numerous tortuous collateral arteries in the porta hepatis some of which were thought to be capsular (Fig. 2). The liver was smaller than before and the circulation through it was slower. Even so, large hepatic veins were again demonstrated on the later films and the liver was much less vascular than before. Repeat blood volume studies (Table) showed a marked reduction in the total blood volume with a fall in the plasma volume to within the normal range. With this there was a rise in venous haematocrit.

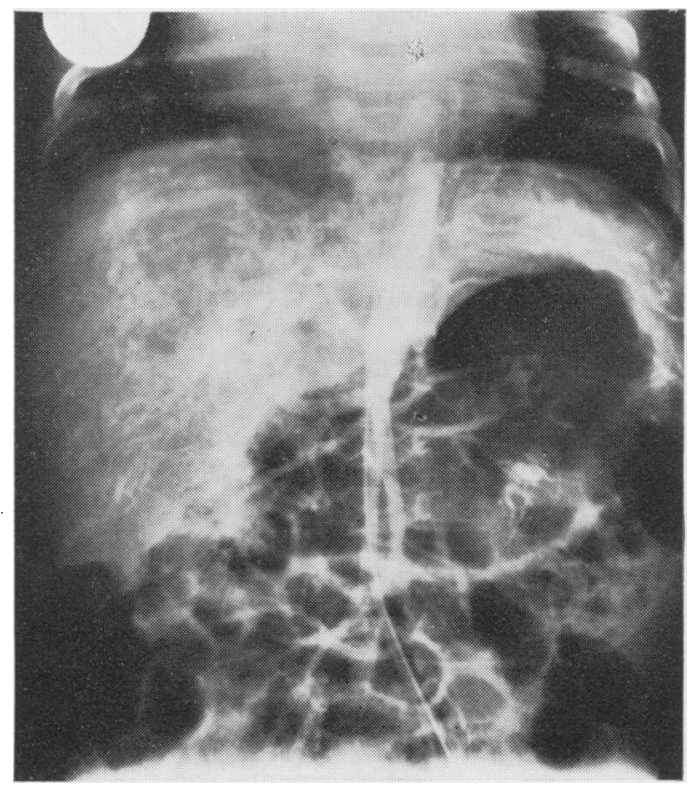

Fig. 2 Postoperative aortogram. The arboreal phase shows the hepatic artery occluded $2 \mathrm{~cm}$ from the origin, but some intrahepatic branches fill through collateral vessels in the porta hepatis. 
When seen on 4 July 1969 the child was well, his weight had increased to $8.5 \mathrm{~kg}$, and his motor development was normal. The liver was just palpable and no bruit could be heard. A repeat chest film showed a normal cardiac outline (cardiothoracic ratio $48 \%$ ) and normal lung markings. He was continuing to do well when last seen in April 1970.

\section{Discussion}

As already mentioned, the clinical syndrome of cutaneous haemangiomatosis, hepatomegaly with multiple haemangiomata, and high output cardiac failure has a mortality of 80 to $90 \%$ when treated by conventional methods (DeLorimier et al, 1967). If cardiac failure is present while the hepatic haemangioma is still in the growing phase (during the first nine months to a year of life), control of heart failure, even if successful initially, may become impossible as the lesion enlarges.

Recent reports (Fost and Esterley, 1968; Zarem and Edgerton, 1967) have shown that systemic corticosteroid therapy may considerably reduce the size of cutaneous haemangiomata within two weeks of starting treatment, and recently Goldberg and Fonkalsrud (1969) have reported the successful use of such therapy in one patient with hepatic haemangioma occupying approximately half the liver volume. In our patient there was no shrinking of the skin lesions or evidence of improvement during the period of administration of prednisone but the dose given was lower than that used by the other groups. Radiotherapy has been reported (Wilson and Haggard, 1960) to be of some benefit in both skin and hepatic haemangiomatosis but the combination of prednisone and radiotherapy failed to benefit this patient as assessed clinically and also by objective criteria, including liver scan and chest radiographs.

Surgical methods of treatment have included resection of the lesion (Siderys, Moore, and Shumacker, 1962) and in one case hepatic artery ligation (DeLorimier et al, 1967). Resection in the present case was impossible as the whole of the liver was involved, and although partial hepatectomy would have reduced the arteriovenous shunt the procedure is a major one, and unlikely to have been tolerated by the patient. Hepatic artery ligation was thought to be the simplest and safest procedure. Although it was realized that this might not completely stop the arteriovenous shunt because of the development of collaterals, it was felt that it would be sufficient to control the heart failure until spontaneous regression of the haemangiomata occurred and the whole lesion underwent involution. This was certainly achieved: the cardiac failure disappeared very quickly following the ligation and has not returned. Arteriovenous shunts wherever sited, if sufficiently large, are usually accompanied by a high blood volume due to an increase in plasma volume (Warren, Elkin, and Nickerson, 1951). The return of the blood volume to normal is another confirmatory sign that the hepatic arteriovenous shunt in this infant had been decreased by hepatic artery ligation.

We are indebted to Dr Ursula Shelley and Professor Eric Stroud for their care of this patient, and to $\mathrm{Dr}$ L. M. Blendis for the plasma volume measurements.

\section{References}

DeLorimier, A. A., Simpson, E. B., Baum, R. S., and Carlsson, E. (1967). Hepatic artery ligation for hepatic haemangiomatosis. New Engl. J. Med., 277, 333-337.

Fost, N. C., and Esterly, N. B. (1968). Successful treatment of juvenile haemangiomas with prednisone. J. Pediat., 72, 351-357.

Goldberg, S. J., and Fonkalsrud, E. (1969). Successful treatment of hepatic haemangioma with corticosteroids. J. Amer. med. Ass., 208, 2473-2474.

Shumacker, H. B., Jr. (1942). Haemangioma of the liver discussion of symptomatology and report of patient treated by operation. Surgery, 11, 209-222.

Siderys, H., Moore, T. C., and Shumacker, H. B., Jr. (1962). Left hepatic lobectomy for haemangioma of the liver in the newborn. Surgery, 52, 502-504.

Wilson, C. J., and Haggard, M. E. (1960). Giant vascular tumours and thrombocytopenia. Arch. Derm., 81, 432-437.

Warren, J. V., Elkin, D. C., and Nickerson, J. L. (1951). The blood volumes in patients with arteriovenous fistulas. J. clin. Invest., 30, 220-226.

Zarem, H. A., and Edgerton, M. T. (1967). Induced resolution of cavernous haemangiomas following prednisolone therapy. Plast. reconstr. Surg., 39, 76-83. 